\title{
Study of Lactic Acid Bacteria Community From Raw Milk of Iranian One Humped Camel and Evaluation of Their Probiotic Properties
}

\author{
Nafiseh Davati ${ }^{1}$; Farideh Tabatabaee Yazdi ${ }^{1}$; Saeed Zibaee ${ }^{2, *}$; Fakhri Shahidi ${ }^{1}$; Mohammad \\ Reza Edalatian ${ }^{1}$ \\ ${ }^{1}$ Department of Food Science and Technology, Ferdowsi University of Mashhad, Mashhad, IR Iran \\ ${ }^{2}$ Department of Veterinary Research and Biotechnology, Razi Vaccine and Serum Research Institute, Mashhad, IR Iran \\ ${ }^{*}$ Corresponding author: Saeed Zibaee, Department of Veterinary Research and Biotechnology, Razi Vaccine and Serum Research Institute, Mashhad, IR Iran. Tel: +98-9153045919, Fax: \\ +98-5118420430, E-mail: s.zibaee@mrazi.ac.ir
}

Received: December 9, 2013; Revised: April 13, 2014; Accepted: April 22, 2014

\begin{abstract}
Background: Camel milk is amongst valuable food sources in Iran. On the other hand, due to the presence of probiotic bacteria and bacteriocin producers in camel milk, probiotic bacteria can be isolated and identified from this food product.

Objectives: The objectives of the present research were the isolation and molecular identification of lactic acid bacteria from camel milk and evaluation of their probiotic properties.

Materials and Methods: A total of ten samples of camel milk were collected from the Golestan province of Iran under aseptic conditions. Bacteria were isolated by culturing the samples on selective medium. Isolates were identified by amplification of the 16S rDNA and Internal Transcribed Spacer (ITS) region between the 16S and 23S rRNA genes by Polymerase Chain Reaction (PCR) and were then screened and grouped by the Amplified Ribosomal DNA Restriction Analysis (ARDRA) method. To evaluate probiotic properties, representative isolates of different ARDRA profiles were analyzed. The antimicrobial activity of Lactic Acid Bacteria (LAB) against Pediococcus pentosaceus, Escherichia coli and Bacillus cereus was examined by the agar diffusion assay. Acid and bile tolerance of isolates were evaluated.

Results: A total of 64 isolates were analyzed based on biochemical tests and morphological characteristics. The most frequently isolated LAB was Enterococci. Weissella, Leuconostoc, Lactobacilli and Pediococci were less frequently found. Based on restriction analysis of the ITS, the isolates were grouped into nine different ARDRA patterns that were identified by ribosomal DNA sequencing as P. pentosaceus, Enterococcus faecium strain Y-2, E. faecium strain JZ1-1, E. faecium strain E6, E. durans, E. lactis, Leuconostoc mesenteroides, Lactobacillus casei and Weissella cibaria. The results showed that antimicrobial activity of the tested isolates was remarkable and $P$. pentosaceus showed the most antibacterial activity. In addition, E. durans, E. lactis, L. casei and P. pentosaceus were selected as probiotic bacteria.

Conclusions: This study revealed the presence of bacteriocin-producing bacteria and probiotic bacteria in camel milk from the Golestan province of Iran.
\end{abstract}

Keywords: Milk; Camel; Probiotic; Antibacterial

\section{Background}

Although the world's share of camel milk in comparison with other domesticated animals is very low yet the milk produced by camels in drought areas can be a valuable food source for the human population (1). Iran is a country with vast arid regions. Under such conditions, the only livestock, which can successfully survive, is camel. However, camel milk has no access to the market and due to its poor keeping quality, it cannot be used as fresh and goes to waste. During the peak production season, it can be saved and effectively utilized through conversion to yoghurt and drinking yoghurt using a starter culture of Lactic Acid Bacteria (LAB). In fermented products from milk, LAB as starter culture play an important role in the process of fermentation. The microbiological quality of milk and milk products is influenced by the initial flora of raw milk (2). It has been recognized that LAB are capable of producing inhibitory substances such as organic acid, hydrogen peroxide, bacteriocin and diacetyl (3). Natural antimicrobials produced by microbes, especially
LAB, have been widely used as chemotherapeutic agents that can control the growth of microbial pathogens (4).

One of the most significant groups of probiotic organisms is LAB. Probiotics are beneficial bacteria that favorably alter the intestinal microflora balance, inhibit the growth of pathogenic bacteria, promote digestion, boost immune function and increase resistance to infection. Other physiological benefits of probiotics include removal of carcinogens, lowering of cholesterol and immunostimulants, lowering the effect of allergies, alleviation of lactose intolerance. They must survive exposure to harsh conditions imposed by gastric acids $(\mathrm{pH}=3)$, bile and digestive enzymes ( $0.4 \%$ bile salts) (5). A good tool for molecular identification of LAB is restriction analysis of 16S-23S rRNA intergenic spacer regions (6).

\section{Objectives}

The objectives of the present research were the isolation

Copyright (C) 2015, Ahvaz Jundishapur University of Medical Sciences. This is an open-access article distributed under the terms of the Creative Commons Attribution-NonCommercial 4.0 International License (http://creativecommons.org/licenses/by-nc/4.0/) which permits copy and redistribute the material just in noncommercial usages, provided the original work is properly cited. 
and molecular identification of LAB from camel milk and evaluation of their probiotic properties.

\section{Materials and Methods}

\subsection{Isolation of Lactic Acid Bacteria}

A total of ten samples of camel milk were collected from the Golestan province of Iran under aseptic conditions and appropriate dilutions of samples were plated onto four groups of plates including de Man Rogosa (MRS) agar and vancomycin, MRS agar alone, M17 agar, and Kanamycin Aesculin Azide (KAA) agar (Merck, Germany). Plates were incubated at $20^{\circ} \mathrm{C}, 37^{\circ} \mathrm{C}, 45^{\circ} \mathrm{C}$ for 48 hours under anaerobic conditions (using anaerocult $₫ A$ gas packs, Merck, Germany). Colonies with different morphologies were counted and purified by re-streaking on the same medium. Gram staining, catalase test and microscopic observations were performed for preliminary screening of LAB. The isolated LAB strains were analyzed by gas production, $6.5 \% \mathrm{NaCl}$ tolerance, growth at $10^{\circ} \mathrm{C}$, $45^{\circ} \mathrm{C}, \mathrm{pH} 4.4$ and $\mathrm{pH} 9$ and 6 . The strains were identified at genus level (7).

\subsection{Molecular Identification of Lactic Acid Bacteria Species}

\subsubsection{DNA Extraction}

For DNA extraction, single colonies were resuspended in $50 \mu \mathrm{L}$ of sterile deionized water. Next, $50 \mu \mathrm{L}$ of chloroform/isoamyl alcohol (24:1) was added to the suspensions, and after vortexing, the mixture was centrifuged at $16000 \mathrm{~g}$ for five minutes at $4^{\circ} \mathrm{C}$. Then, $5 \mu \mathrm{L}$ of the upper aqueous phase was used as a source of DNA template for the PCR reaction (8).

\subsubsection{Amplification of the Internally Transcribed Spacer (ITS) Region and Analysis of the Amplified Ribosomal DNA}

The primers used for the amplification of the ITS region between the $16 \mathrm{~S}$ and $23 \mathrm{~S}$ rRNA genes were B27F (5' -AGAGTTTGATCCTGGCTCAG-3' ) and L1R (5' -CAAGGCATCCACCGT-3' ) (Bioneer, Korea) (9). The Polymerase Chain Reaction (PCR) was carried out by mixing $5 \mu \mathrm{L}$ of each extracted DNA with $25 \mu \mathrm{L}$ of $2 \mathrm{X}$ PCR Master kit (composition of $1 \mathrm{X}$ solution: 0.5 M Tris-HCl, $1.5 \mathrm{mM}$ $\mathrm{MgCl}_{2}-200 \mu \mathrm{M}$ dATP, $200 \mu \mathrm{M}$ dCTP, $200 \mu \mathrm{M}$ dGTP and 200 $\mu \mathrm{M}$ dTTP and 0.04 Units/ul Taq) (SinaClon, Iran), 1 LL Oligo forward (10 picomole $/ \mu \mathrm{L}), 1 \mu \mathrm{L}$ Oligo reverse (10 picomole/ $\mu \mathrm{L})$ and $18 \mu \mathrm{L}$ Sterile deionized water.

The amplification was achieved by 40 PCR cycles using the following procedure: first denaturation was performed at $94^{\circ} \mathrm{C}$ for five minutes, then 40 cycles at $94^{\circ} \mathrm{C}$ for one minute, $42^{\circ} \mathrm{C}$ for one minute and finally $72^{\circ} \mathrm{C}$ for one minute. After a final extension at $72^{\circ} \mathrm{C}$ for 10 minutes, the tubes were cooled to $4^{\circ} \mathrm{C}(10)$. The $16 \mathrm{~S}$ rRNA- ITS gene
PCR product from each LAB isolate was cut with restriction endonuclease enzyme: Taql and Hhal (Fermentas, USA), following the manufacturer's instructions. The reaction mixture was then incubated at $65^{\circ} \mathrm{C}$ and $37^{\circ} \mathrm{C}$ for Taq I and Hhal, respectively for 1.5 hour. The Amplified Ribosomal DNA Restriction Analysis (ARDRA) profiles were examined using $1.5 \%(\mathrm{w} / \mathrm{v})$ agarose gels in $0.5 \mathrm{X}$ Tris/ Borate/Ethylenediaminetetraacetic acid (TBE) buffer at 75 $\mathrm{V}$ for 90 minutes with a DNA ladder (GeneRuler ${ }^{\mathrm{TM}} 100 \mathrm{bp}$ ) (Fermentas, USA).

\subsubsection{Amplification of 16S rDNA Genes}

Representative isolates of different ARDRA profiles were amplified by PCR. The primers used for the amplification of 16S rDNA genes were B27F ( $5^{\prime}$-AGAGTTTGATCCTGGCTCAG-3' ) and U1492R (5' -ACGTGGTTTGAAGAGATTTTCG-3' ) (Bioneer, Korea). The PCR was carried out by mixing $5 \mu \mathrm{L}$ of each extracted DNA with $25 \mu \mathrm{L}$ of 2 X PCR Master kit (SinaClon, Iran), $1 \mu \mathrm{L}$ Oligo forward (10 picomole $/ \mu \mathrm{L}$ ), $1 \mu \mathrm{L}$ Oligo reverse (10 picomole $/ \mu \mathrm{L}$ ) and $18 \mu \mathrm{L}$ sterile deionized water. The amplification was achieved by 40 PCR cycles using the following procedure: first denaturation at $94^{\circ} \mathrm{C}$ for five minutes, then 40 cycles at $94^{\circ} \mathrm{C}$ for one minute, $56^{\circ} \mathrm{C}$ for one minute and $72^{\circ} \mathrm{C}$ for one minute. After a final extension at $72^{\circ} \mathrm{C}$ for 10 minutes, the tubes were cooled to $4^{\circ} \mathrm{C}(10)$. Representative amplicons of the different ARDRA profiles were purified and sequenced by Macrogen Sequencing Service (Korea).

\subsection{Antimicrobial Activity Evaluation of Lactic Acid Bacteria}

Pediococcus pentosaceus subsp. aureus ATCC 25923, Escherichia coli O157: H7 and Bacillus cereus ATCC 10876, were used as indicator strains. These were grown in Nutrient Agar (NA) at $37^{\circ} \mathrm{C}$. Antimicrobial activity of LAB against E. coli $\mathrm{O} 157$ and B. cereus was determined by the agar well diffusion assay and against $S$. aureus subsp. aureus by disc diffusion assay. Isolates were grown in MRS and M17 broth (Merck, Germany) at $37^{\circ} \mathrm{C}$ for 24 hours. Each indicator bacteria was grown in nutrient broth (Merck, Germany) at $37^{\circ} \mathrm{C}$ for 24 hours. Furthermore, $100 \mu \mathrm{L}$ of this broth culture of pathogenic bacteria was cultured on Muller-Hinton Agar (MHA) (Merck, Germany). The resulting supernatants of overnight culture of representative isolates were neutralized to $\mathrm{pH}=6.5-7.0$, centrifuged at $14000 \mathrm{rpm}$ for five min, and filtered through a $0.20 \mu \mathrm{m}$ pore membrane (Millipore, USA). Next, wells of $6 \mathrm{~mm}$ in diameter were created in these agar plates and filled with $50 \mu \mathrm{L}$ of each isolates supernatant (11). Sterile discs (6 mm in diameter) were soaked with culture filtrate of each isolate and placed on a $100 \mathrm{~mm}$ plate for the disc diffusion assay (12).

\subsection{Acid Tolerance}

In this study, representative isolates from each profile were used for evaluation of probiotic properties. Isolates 
were grown for six hours in MRS broth at $37^{\circ} \mathrm{C}$. An aliquot of $1 \mathrm{~mL}$ of the six-hour old culture was inoculated in 100 $\mathrm{mL}$ of MRS broth, which had its $\mathrm{pH}$ adjusted to 3 or 7. Bacterial growth was monitored by determination of optical density at $620 \mathrm{~nm}$ after 24 hours of incubation at $37^{\circ} \mathrm{C}$. The percentage difference between the variation of optical density at $\mathrm{pH}=7.0(\Delta \mathrm{OD} \mathrm{pH}=7)$ and the variation of optical density at $\mathrm{pH}=3(\Delta \mathrm{OD} \mathrm{pH}=3)$ would give an index of surviving isolates that can be expressed as follows (Equation 1):

$$
\text { (1) Surviving }(\%)=\frac{\Delta \mathrm{OD}(\mathrm{pH} 7)-\Delta \mathrm{OD}(\mathrm{pH} 3)}{\Delta \mathrm{OD}(\mathrm{pH} 7) \times 100}
$$

Classification criteria of probiotics included: good if the isolate survived at pH 3 after 24 hour; poor if the isolate did not survive in any experimental condition. An isolate survived if it demonstrated a surviving percentage equal to or greater than $50 \%(13,14)$.

\subsection{Bile Salt Tolerance}

The tolerance of isolates to Bile Salts (BS) was evaluated in MRS supplemented with Bile Salts. Isolate cultures were grown for six hours in MRS broth at $37^{\circ} \mathrm{C}$. An aliquot of $1 \mathrm{~mL}$ of the six-hour old culture was inoculated in 100 $\mathrm{mL}$ of MRS broth with $0.4 \%$ (w/v) bile salts (Sigma, Germany). Bacterial growth was monitored by determination of optical density at $620 \mathrm{~nm}$ after six and 24 hours of incubation at $37^{\circ} \mathrm{C}$. The percentage difference between the variation of optical density of the culture without bile salts ( $\triangle \mathrm{OD} 0 \% \mathrm{BS}$ ) and the variation of optical density of culture containing $0.4 \%$ bile salts ( $\triangle \mathrm{OD} 0.4 \% \mathrm{BS}$ ) would give an index of isolates surviving that can be expressed as follows (Equation 2):

$$
\text { (2) Surviving }(\%)=\frac{\Delta \mathrm{OD}(0 \% \mathrm{BS})-\Delta \mathrm{OD}(0.4 \% \mathrm{BS})}{\Delta \mathrm{OD}(0 \% \mathrm{BS})}
$$

Classification criteria of probiotics included: excellent if the isolate survived at $0.4 \%$ bile salt after 24 hours; very good if the isolate survived in $0.4 \%$ bile salt after six hours; poor if the isolate did not survive in any experimental condition. An isolate survived if it demonstrated a surviving percentage equal to or greater than $50 \%(5,13,14)$.

\section{Results}

\subsection{Isolation and Identification of Lactic Acid Bac- teria}

A total of 64 bacteria were isolated from camel milk samples. The results of colony counts from different media and temperatures are shown in Table 1 and Figure 1. This Figure shows that the most colony-forming units per $1 \mathrm{~mL}(8.79 \pm 0.2)$ was obtained from MRS agar media at $20^{\circ} \mathrm{C}$. All these isolates were gram positive, catalase negative rods or cocci. These strains were classified at the genus level based on biochemical tests and morphological properties. Results indicated that the 64 isolates were separated to five groups. These five groups included Leuconostoc, Lactobacillus, Enterococcus, Weissella and Pediococcus genus (Figure 2). Figure 2 showed that Enterococcus spp were dominant (51\%) in comparison with other LAB genus. The restriction enzyme Taq I for restriction digestions of the amplicons were able to differentiate all 62 LAB isolates into nine restriction patterns. These ARDRA profiles are shown in Figure 3 and listed in Table 2.

Table 1. Log Colony Forming Unit $\left(\mathrm{CFUmL}^{-1}\right)$ at Different Temperatures $^{\mathrm{a}}$

\begin{tabular}{lccc}
\hline Isolation Medium & \multicolumn{3}{c}{ Isolation Temperature, ${ }^{\circ} \mathbf{C}$} \\
\cline { 2 - 4 } & $\mathbf{2 0}$ & $\mathbf{3 7}$ & $\mathbf{4 5}$ \\
\hline KAA & $5.81 \pm 0.02$ & $6.39 \pm 0.05$ & $8.01 \pm 0.05$ \\
MRS + Vancomycin & $7.61 \pm 0.07$ & $7.27 \pm 0.06$ & $5.84 \pm 0.1$ \\
MRS & $8.79 \pm 0.2$ & $8.30 \pm 0.03$ & $7.30 \pm 0.15$ \\
M17 & $8.16 \pm 0.03$ & $8.69 \pm 0.1$ & $8.50 \pm 0.04$ \\
\hline${ }^{a}$ Data are presented as mean \pm SD. & &
\end{tabular}

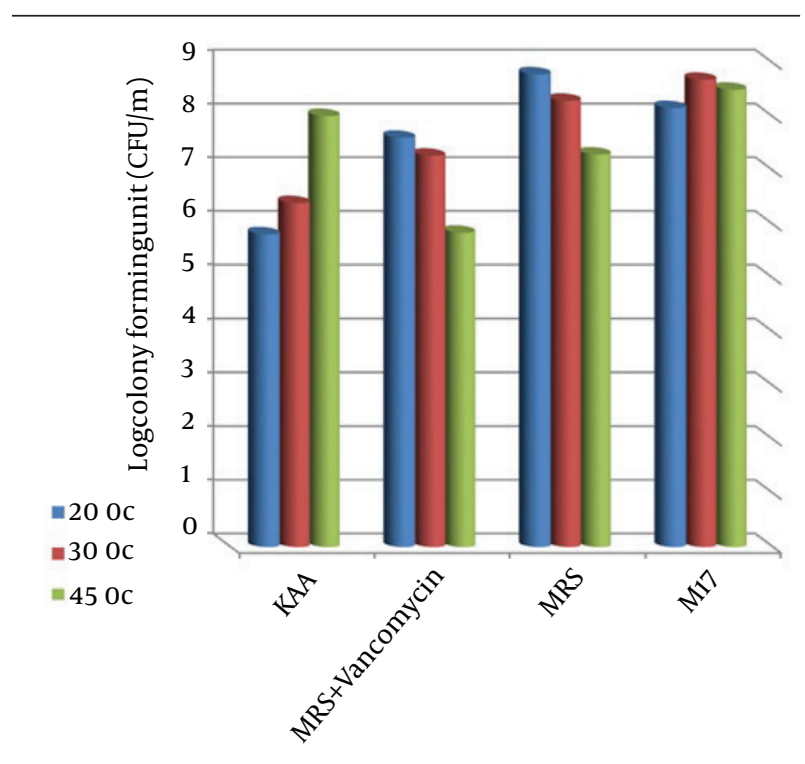

Figure 1. $\log _{10}$ Colony Forming Unit $\left(\mathrm{CFU} \mathrm{mL}{ }^{-1}\right)$ at Different Temperatures

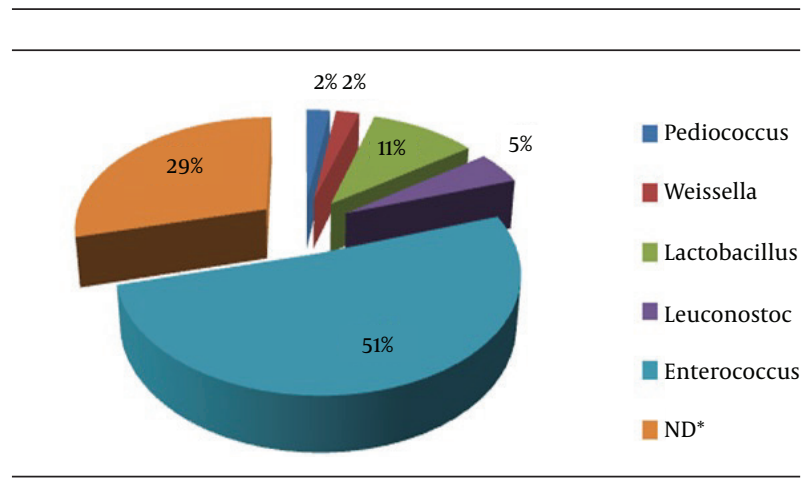

Figure 2. Repartition of Different Genus in Lactic Acid Bacteria Community of Camel Milk 
Davati N et al.

Figure 3. Amplified 16S-23S rDNA Restriction Analysis (ARDRA) Profiles With Taq I

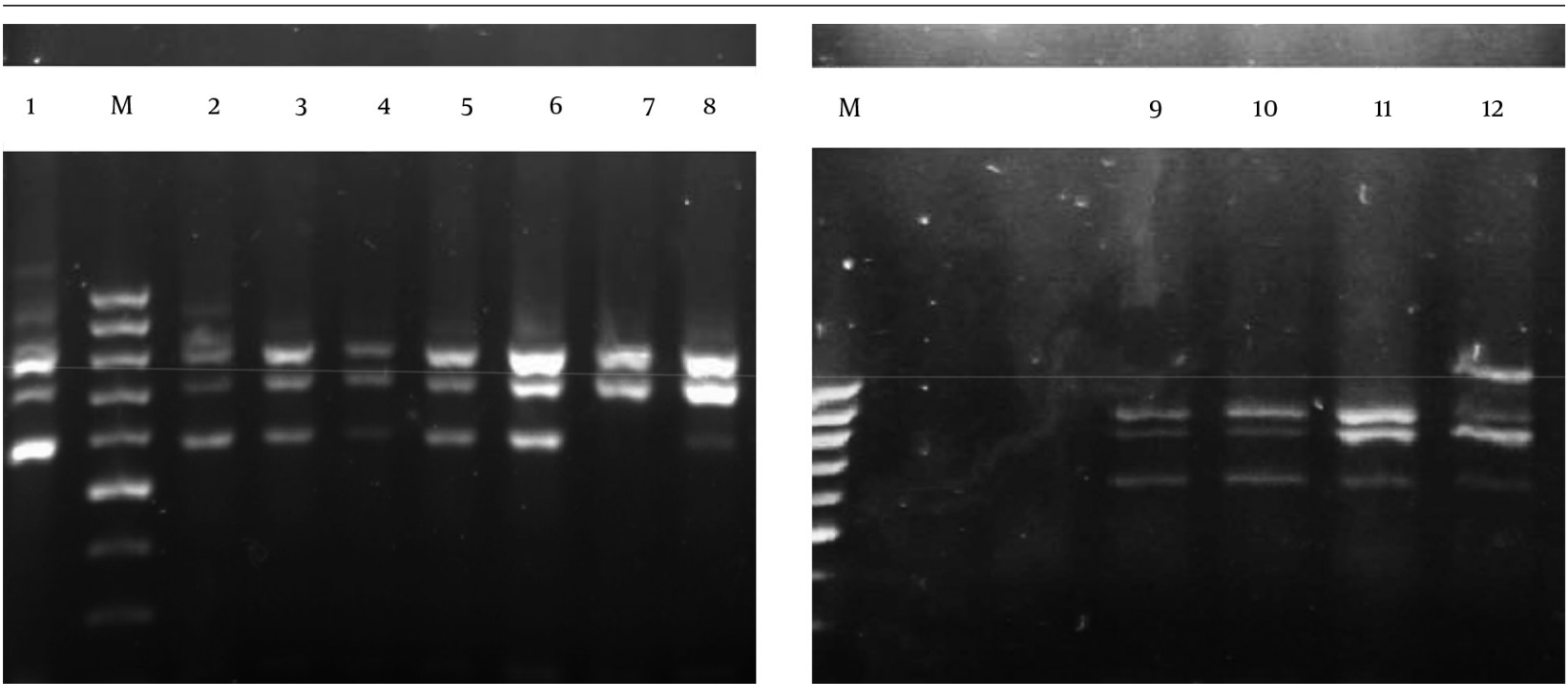

M;100 bp marker, 1; E. durans strain R02-23, 2; E. faecium strain E6, 3; E. lactis, 4; E. faecium strain Y-2, 5; E. lactis, 6; E. lactis, 7; E. faecium strain JZ1-1, 8; W. cibaria 9; P. pentosaceus strain KDLLL3-3, 10; P. pentosaceus strain KDLLL3-3, 11; L. casei and 12; L. mesenteroides strain 54.

\begin{tabular}{lccc}
\hline \multicolumn{2}{l}{ Table 2. ARDRA Profiles and Identification of Lactic Acid Bacteria Isolated From Camel Milk } \\
\hline ARDRA, Pattern & Closest Relative & Representative Isolate & Identity $^{\text {a }}$ \\
\hline $\mathbf{1}$ & Enterococcus durans strain R02-23 & $4-5-6-7-11-12-15-19-23-24-41-56-64$ & 99 \\
$\mathbf{2}$ & Enterococcus faecium strain E6 & $8-9-14-16-21-26-31-37-40-43-55-58$ & 99 \\
$\mathbf{3}$ & Enterococcus lactis & $17-18-20-30-38-51-59-60$ & 98 \\
$\mathbf{4}$ & Enterococcus faecium strain Y-2 & $1-2-10-13-27-28-57-62-63$ & 99 \\
$\mathbf{5}$ & Enterococcus faecium strain JZ1-1 & $22-33-50-61$ & 99 \\
$\mathbf{6}$ & Weissella cibaria & $32-36$ & 98 \\
$\mathbf{7}$ & Pediococcus pentosaceus & $3-52$ & 99 \\
$\mathbf{8}$ & Lactobacillus casei & $25-34-35-39-42-46-47-48-49-53$ & 98 \\
$\mathbf{9}$ & Leuconostoc mesenteroides & $29-44-45-54$ & 99 \\
\hline
\end{tabular}

a Data are presented as (\%).

Representative isolates from each profile were analyzed for their 165 rDNA sequences. Homology searches of the sequences revealed (with 98 - 99\% homology) that profile 1 belonged to E. durans strain R02-23, profile 2 belonged to E. faecium strain E6, profile 3 belonged to E. lactis, profile 4 belonged to $E$. faecium strain Y-2, profile 5 belonged to $E$. lactis, profile 6 belonged to E. lactis, profile 7 belonged to E. faecium strain JZ1-1, profile 8 belonged to L. mesenteroides strain 54, profile 9 belonged to $P$. pentosaceus, profile 10 belonged to $P$. pentosaceus, profile 11 belonged to $L$. $\mathrm{Ca}$ sei and profile 12 belonged to W. cibaria (Figure 3). Results showed that the restriction enzyme Hha I could not differentiate among isolates based on restriction enzyme digestion profiles.

\subsection{Lactic Acid Bacteria Antimicrobial Activity}

Figure 4 illustrates the zones of inhibition against pathogenic bacteria under study. In general, the studied isolates had inhibitory activity against pathogenic bacteria, because the inhibition was scored positive if the diameter of the clear zone around the colonies was $0.5 \mathrm{~mm}$ or larger. According to Figure 4, isolates P. pentosaceus, $W$. cibaria, E. faecium strain E6, E. lactis, E. durans strain R02-2, L. casei and L. mesenteroides strain 54, respectively had the highest inhibitory activity against $S$. aureus subsp. aureus ATCC 25923 and isolates P. pentosaceus, E. durans strain R02-2, E. faecium strain E6, E. faecium strain Y-2, L. mesenteroides strain 54, L. casei and E. lactis, respectively had the highest inhibitory spectrum against B. cereus ATCC 10876. Also, isolates $P$. pentosaceus, $W$. cibaria, E. lactis, E. durans strain R02-2, E. faecium strain E6 and E. faecium strain JZ1-1, respectively had the highest inhibitory spectrum against E. coli $\mathrm{O} 157 \mathrm{H} 7$. Isolate P. pentosaceus indicated the highest inhibition effect to growth indicator bacteria. 
Davati Net al.

Figure 4. Inhibition Zones of Lactic Acid Bacteria against pathogenic bacteria
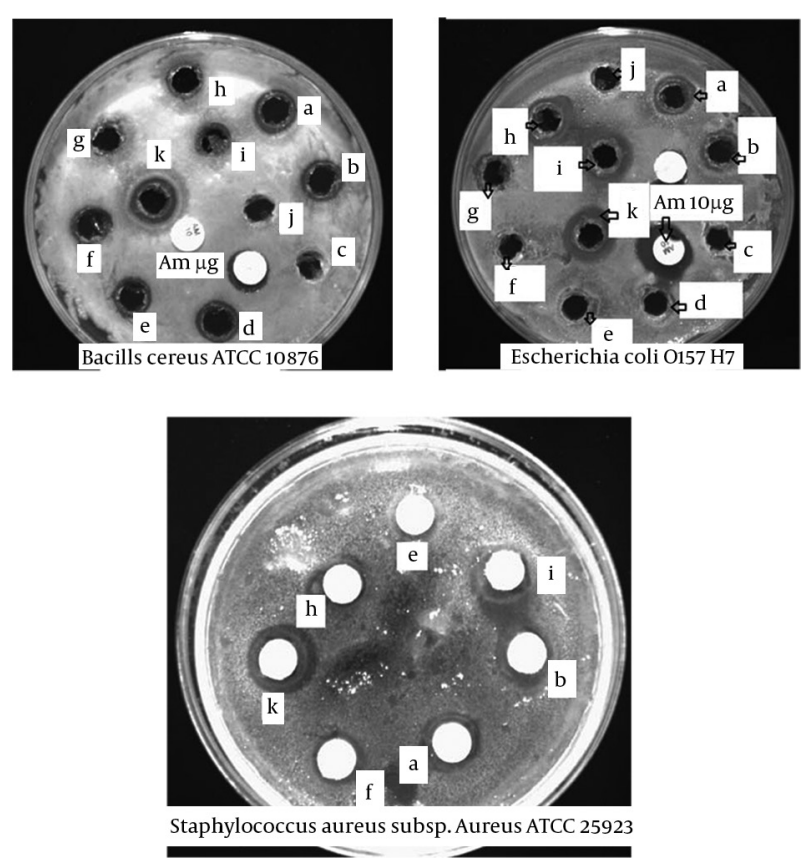

B. cereus ATCC 10876, E. coli $\mathrm{O} 157 \mathrm{H7}$ (well diffusion assay) and S. aureus subsp. aureus (disc diffusion assay); a, E. durans strain R02-2; b, E. faecium strain E6; c, control - (MRS without bacteria); d, E. faecium strain Y-2; e, L. mesenteroides strain 54; f, L. casei; g, E. faecium strain JZ1-1; h, E. lactis; I, W. Cibaria; j, control-(MRS without bacteria); k, P. pentosaceus.

Table 3. Surviving Percentage of Selected Isolates in de Man Rogosa Broth at pH 3 and de Man Rogosa Broth Supplemented With $0.4 \%$ Bile Salts After Six and Twenty-Four Hours at $37^{\circ} \mathrm{C}$

\begin{tabular}{lcccc}
\hline \multirow{2}{*}{ Strain } & \multicolumn{2}{c}{$\mathbf{0 . 4 \%}$ Bile Salts } & \multicolumn{2}{c}{$\mathbf{p H}=\mathbf{3}$} \\
\cline { 2 - 5 } & $\mathbf{6 ~ h}$ & $\mathbf{2 4} \mathbf{~ h}$ & $\mathbf{6 ~ h}$ & $\mathbf{2 4} \mathbf{~ h}$ \\
\hline $\begin{array}{l}\text { E. duransstrain } \\
\text { Ro2-23 }\end{array}$ & 51.98 & 51.75 & 88.81 & 81.10 \\
\hline E. faecium strain E6 & 70.98 & 69.36 & 47.51 & 44.23 \\
\hline E. lactis & 60.05 & 47.73 & 62.06 & 53.04 \\
\hline L. casei & 58.76 & 55.81 & 78 & 75.80 \\
\hline L. mesenteroides & 39 & 35.54 & 46.51 & 46.19 \\
\hline P. pentosaceus & 95 & 92.34 & 98.83 & 90.96 \\
\hline W. cibaria & 46.57 & 44.92 & 50.84 & 50.24 \\
\hline
\end{tabular}

\subsection{Acid Tolerance and Bile Salt Tolerance}

Among the seven selected representative isolates under the acidic conditions using the rapid selective method, five isolates, namely E. durans, L. casei, E. lactis, P. pentosaceus and W. cibaria, showed good tolerance. Also, four isolates, namely E. durans, E. faecium, L. casei, P. pentosaceus, demonstrated excellent capacity and one isolate, namely E. lactis, demonstrated good capacity to resist bile salts by presenting a surviving percentage greater than $50 \%$ under exposure to $0.4 \%$ bile salts after six hours at $37^{\circ} \mathrm{C}$ (Table 3 ).

\section{Discussion}

This study showed that in preliminary screening of camel milk LAB community at the genus level, Enterococcus spp were dominant in comparison with other LAB genus. Because of high salt presence in camel milk compared to other livestock animals, large numbers of Enterococcus spp. can live in camel milk. It was found that the selected primers were able to amplify the ITS region between the $16 S$ and $23 \mathrm{~S}$ rRNA genes of each LAB isolate from camel milk. In this study, ARDRA facilitated the screening and identification of a large number 62 of LAB isolates obtained from camel milk. Also, other researchers have reported the merits of ARDRA for rapid grouping and identification of isolates of LAB (15). This study revealed that most of the isolates can inhibit the growth of S. aureus, B. cereus and E. coli, because the clear zone around the colonies was $0.5 \mathrm{~mm}$ or larger. Consuming camel milk and its fermented products can help human health and protect the body against occurrences of food poisoning (16).

In the point of view of probiotic potential, E. durans, $L$. casei, E. lactis and P. pentosaceus isolated from camel milk were selected as probiotic bacteria. In another study on camel milk, Yateem et al. (17) showed the presence of $L$. plantarum, L. pentosus and L. lactis as probiotic LAB in raw camel milk. This study suggests that camel milk is a potential source for the isolation of probiotic LAB strains and can be considered good for health with antibacterial properties against pathogenic bacteria because of the presence of bacteriocin-producing strains such as Enterococcus spp. Weissella spp. and Pediococcus spp.

\section{Acknowledgements}

The authors gratefully thank the staff of the biotechnology laboratory of Mashhad Razi Vaccine and Serum Research Institute.

\section{Authors' Contributions}

Farideh Tabatabaee Yazdi and Saeed Zibaee developed the original idea and were the sponsors. Nafiseh Davati performed the experiments, analyzed the data, wrote the preliminary draft and revised the manuscript. Farideh Tabatabaee yazdi, Saeed Zibaee, Fakhri Shahidi and Mohammad Reza Edalatian were the advisors.

\section{Funding/Support}

This study was financially supported by the Ferdowsi University of Mashhad and Mashhad Razi Vaccine and Serum Research Institute.

\section{References}

1. Sweet LE. Camel Raiding of North Arabian Bedouin: A Mechanism of Ecological Adaptation1. Am Anthropol. 1965;67(5):1132-50.

2. Ahmed T, Kanwal R. Biochemical characteristics of lactic acid 
producing bacteria and preparation of camel milk cheese by using starter culture. Pak Vet J. 2004;24(2):87-91.

3. Mishra C, Lambert J. Production of anti-microbial substances by probiotics. Asia Pac J Clin Nutr. 1996;5(1):20-4.

4. Farah Z. Camel milk properties and products.: Swiss Centre for Development Cooperation in Technology and Management;1996.

5. Saarela M, Mogensen G, Fonden R, Matto J, Mattila-Sandholm T. Probiotic bacteria: safety, functional and technological properties.J Biotechnol. 2000;84(3):197-215.

6. Jensen MA, Webster JA, Straus N. Rapid identification of bacteria on the basis of polymerase chain reaction-amplified ribosomal DNA spacer polymorphisms. Appl Environ Microbiol. 1993;59(4):945-52.

7. Salminen S, von Wright A, Ouwehand A. Lactic acid bacteria: microbiology and functional aspects.: Marcel Dekker; 2004.

8. Ruiz-Barba JL, Maldonado A, Jimenez-Diaz R. Small-scale total DNA extraction from bacteria and yeast for PCR applications. Anal Biochem. 2005;347(2):333-5.

9. Mora D, Fortina MG, Nicastro G, Parini C, Manachini PL. Genotypic characterization of thermophilic bacilli: a study on new soil isolates and several reference strains. Res Microbiol. 1998;149(10):711-22.

10. Cisem B. Isolation and Molecular Characterization of Lactid Acid Bacteria from Cheese.: Departemen Biotechnology and Bioengeineering. Izmir Institute of Technology Turkey; 2003.
11. Ahn C, Stiles ME. Antibacterial activity of lactic acid bacteria isolated from vacuum-packaged meats. J Appl Bacteriol. 1990;69(3):302-10.

12. Savadogo A, Ouattara CAT, Bassole IHN, Traore AS. Antimicrobial activities of lactic acid bacteria strains isolated from Burkina Faso fermented milk. PakJ Nutr . 2004;3(3):174-9.

13. Pelinescu DR, Sasarman E, Chifiriuc MC, Stoica I, Nohit AM, Avram I, et al. Isolation and identification of some Lactobacillus and Enterococcus strains by a polyphasic taxonomical approach. Rom Biotechnol Lett. 2009;14(2):4225-33.

14. Verdenelli MC, Ghelfi F, Silvi S, Orpianesi C, Cecchini C, Cresci A. Probiotic properties of Lactobacillus rhamnosus and Lactobacillus paracasei isolated from human faeces. Eur $J$ Nutr. 2009;48(6):355-63.

15. Sato H, Yanagida F, Shinohara T, Yokotsuka K. Restriction frag ment length polymorphism analysis of 16S rRNA genes in lactic acid bacteria isolated from red wine. J Biosci Bioeng. 2000;90(3):335-7.

16. Kekkonen RA, Kajasto E, Miettinen M, Veckman V, Korpela R, Julkunen I. Probiotic Leuconostoc mesenteroides ssp. cremoris and Streptococcus thermophilus induce IL-12 and IFN-gamma production. World J Gastroenterol. 2008;14(8):1192-203.

17. Yateem A, Balba MT, Al-Surrayai T, Al-Mutairi B, Al-Daher R. Isolation of lactic acid bacteria with probiotic potential from camel milk. Int J Dairy Sci. 2008;3(4):194-9. 